Research Article

\title{
Annoyance among Staff and Noise Level in a Tertiary Care Hospital in New Delhi, India: A Pilot Study
}

\author{
Aritrik Das', Jugal Kishore ${ }^{2}$
}

${ }^{1}$ Resident, ${ }^{2}$ Director Professor \& Head, Department of Community Medicine, Vardhman Mahavir Medical College \& Safdarjung Hospital, New Delhi, India.

DOI: https://doi.org/10.24321/2454.325X.202012

\section{I $\quad \mathbf{N} \quad \mathbf{F} \quad \mathbf{O}$}

\section{Corresponding Author:}

Aritrik Das, Department of Community Medicine, Vardhman Mahavir Medical College \& Safdarjung Hospital, New Delhi, India.

E-mail Id:

dasaritrik@gmail.com

Orcid Id:

https://orcid.org/0000-0001-8693-5752

How to cite this article:

Das A, Kishore J. Annoyance among Staff and Noise Level in a Tertiary Care Hospital in New Delhi, India: A Pilot Study. Int I Preven Curat Comm Med 2020; 6(3): 10-16.

Date of Submission: 2020-12-07

Date of Acceptance: 2021-01-25

\section{$\begin{array}{llllllll}\mathbf{A} & \mathbf{B} & \mathbf{S} & \mathbf{T} & \mathbf{R} & \mathbf{A} & \mathbf{C} & \mathbf{T}\end{array}$}

Introduction: In India, an area of not less than 100 metres around a hospital is considered a silence zone, with guidelines restricting noise levels at 50dBA during daytime and 40dBA during the night. Annoyance is a known effect of noise exposure.

Objectives: To determine the feasibility of an extensive study on noise in the hospital, annoyance in staff due to hospital noise and its associated factors.

Methods: Noise data was collected from 3 sites, using a Digital Integrating Sound Level Meter, LutronSL-4035SD(ISO-9001,CE,IEC1010) meeting IEC61672 standards. Stratified random sampling of staff was done on basis of noise exposure. A pre-designed, semi-structured questionnaire collected information on sociodemographic and work profile. Annoyance was measured using standardized general purpose noise reaction questionnaire (ISO-TS/ 15666). Data was analysed in SPSS.

Result: Laeq ranged from $56 \mathrm{~dB}$ in nephrology ward to $89.2 \mathrm{~dB}$ at OPD atrium. Maximum noise level was $98.6 \mathrm{~dB}$ in OPD atrium and $86.1 \mathrm{~dB}$ in nephrology ward. Levels at night in ward were higher than during day time. 24 (53.3\%) of the staff said their workplace is noisy, while $26(57.8 \%)$ were annoyed by workplace noise. Annoyance due to hospital noise was associated with age $(p=0.003)$, duration of work in hospital per week $(p=0.04)$, duration of work in current department $(p=0.007)$, noise level $(p=0.04)$ and workplace distance from arterial road $(p=0.02)$.

Conclusion: Hospital noise levels are higher than recommended levels for sensitive zones as per national guidelines and exceed levels inside wards as stipulated by WHO. More than half the study population were annoyed by workplace noise indicating need for interventions. A study throughout the hospital to study noise levels and annoyance among staff following similar methodology is feasible and necessary.

Keywords: Sound Pollution, Hearing, dB, Sleep Disturbances, Annoyance, Speech Intelligibility 


\section{Introduction}

Noise, defined as unwanted sound, has been recognized as a health hazard for a long time. Its effects were initially observed in occupational settings with loud noise, assessing hearing loss in the workers as the primary health effect. ${ }^{1}$ But studies have expanded to cover several non-auditory effects on health due to short term as well as chronic exposure to noise. According to the WHO, almost 1 million healthy life years (DALY) are lost every year due to exposure to environmental noise in European countries. ${ }^{2}$ WHO recommends hospital indoor noise levels of $L A e q(d B)$ less than $30 \mathrm{~dB}$ and LAmax $(\mathrm{dB})$ of less than $40 \mathrm{~dB} .^{3}$ But several studies have shown that hospital noise has been steadily increasing by about $10 \mathrm{~dB}$ LAeq in the last 5 decades ${ }^{4}$ and have been found to be 15-20dB higher than WHO recommended guidelines. ${ }^{5}$ In India, an area of not less than 100 metres around a hospital is considered a silence zone, with guidelines restricting noise levels at $50 \mathrm{dBA}$ during the day and $40 \mathrm{dBA}$ during the night. ${ }^{6}$

Apart from hearing loss, noise can cause increased stress, ${ }^{7}$ changes in blood pressure and heart rate8, sleep disturbance, ${ }^{6}$ annoyance, ${ }^{2}$ tension headaches, ${ }^{9}$ and affect mental health among the staff and patients. It can also delay wound healing, hamper pain management and increase patient readmission rates in patients ${ }^{10}$ while causing detriment in job performance, burnout and hampered well-being among staff. ${ }^{11}$ Annoyance is the most common effect of noise exposure but may be caused due to or accompanied by other responses such as anxiety, stress and exhaustion. ${ }^{12}$ Noise levels below between 50-55 dBA can lead to high annoyance while levels below $50 \mathrm{dBA}$ can lead to moderate annoyance. ${ }^{6}$ Studies have established that short as well long term exposure to noise has an effect on the cardiovascular system. While sudden loud noises cause autonomic and endocrine responses through stress response, long term exposures have been found to increase systolic and diastolic blood pressure, change heart rate, and may lead to diseases like hypertension, ischemic heart disease and stroke. ${ }^{8}$

Noise can affect oral communications i.e. speech interference between patient and staff leading to miscommunication, uncertainty, irritation, frustration, problems in patientstaff relations and medical errors. ${ }^{11}$ How clearly a person speaks so that his speech is understood by the listener is speech intelligibility. While this depends on the speaker and the listener, it also depends on the environment of their conversation. The difference between speech levels and interfering noise levels need to be over $15 \mathrm{~dB}$ for normal hearing subjects. Noise levels for normal speech is around $50 \mathrm{~dB}$. Therefore, background noise above $35 \mathrm{~dB}$ of the environment may reduce the intelligibility of speech. ${ }^{6}$

Hospital noise sources are many and varied. It may be influenced by traffic, construction work from outside, while alarms, bells, patient and staff conversations, cooling vents and others affect noise indoors. The objective of this pilot study is to determine the feasibility of an extensive study on noise levels and speech intelligibility in the hospital, to study the annoyance in staff due to noise in the hospital and the factors associated with it.

\section{Methodology}

This is a cross-sectional study, conducted over a period of 1 month among staff working in a tertiary care teaching institution in New Delhi. Staff who had never worked in the night shift and those who suffer from hearing impairment and/or take ototoxic drugs were excluded from the pilot study, to minimize confounding. The pilot study was conducted on a sample size of 45 , which was $10 \%$ of the sample size for the principal study, which was calculated using the annoyance and negative effects of noise among health care staff as $27.8 \%$ as per the study "Assessment of Noise Annoyance and its Effects on Healthcare Staff Based on Sound Pressure Level and Annoyance Scale" conducted by Parvin Nassiri et al., in 2014, in Tehran, Iran ${ }^{7}$ and taking the absolute error as $5 \%$.

Noise data for the pilot study was collected in the Nephrology ward, OPD atrium and the Super Specialty Block gate. For the nephrology ward, noise levels were recorded in the largest room with patients and at the nursing station. A complete list of employees working at the 3 selected sites of the hospital were obtained. Stratification was done on the basis of common noise exposure, with each sound sampling site considered as a common noise exposure for all those working there and a random sample of the different types of workers in each site were selected for the study. 15 subjects were selected from each site from the study for a total of 45 subjects.

Noise levels were recorded using a Digital Integrating Sound Level Meter, Lutron SL-4035SD (ISO 9001, CE, IEC 1010) meeting the IEC 61672 class 2 standards. The readings are in Decibel, A-weighted (dBA) units representing the sound level measured with the A-weighting network on the sound level meter. Speech intelligibility was measured using STIPA PRO - iOS app meeting the existing IEC 6026816:2011 standards for speech intelligibility. 8 Annoyance among staff was measured using the standardized general purpose (community) noise reaction questionnaires. (ISO TS/15666 standards). ${ }^{9}$

\section{Tool Validation}

A pre-designed, pre-tested, semi-structured questionnaire which was self-administered in English or Hindi consisting of questions on demographic and work-related information, knowledge and perception about noise pollution and its sources in their current workplace and self-reported symptoms due to noise - headache, sleep disturbance, 
low concentration, dizziness, tinnitus, vocal fatigue, gastric discomfort. The questionnaire was prepared after a review of available literature. The questionnaire was content validated by experts on the basis of selection of content, organization of content, language, practicability, feasibility, objectivity, relevance, specificity, validity and reliability. The content was validated from 8 experts and the content validity index was calculated to be 0.8 and deemed as appropriate. Cronbach alpha reliability was also measured for the questionnaire in SPSS version 21 and calculated to be 0.92 overall. The questionnaire was translated to Hindi and verified by two independent experts that the translation was consistent with the original English version.

\section{Data Collection}

Noise data was collected at the nursing station and the central location of the ward in the study and from the outdoor locations. Data was collected on two occasions, on a weekday and a weekend from every site. Where 24-hour monitoring was not possible, noise recording was done for a minimum of $75 \%$ of the day time ( $6 \mathrm{am}$ to $10 \mathrm{pm}$ ) and night time (10 pm to $6 \mathrm{am}$ ).

The device was placed at 1.5-meter distance from the ground using a tripod, and calibration was done before every use. A wind shield was used to prevent interference from reflected noise. The measurement site was located at least $3.5 \mathrm{~m}$ from any acoustically reflective surface other than the ground. If conditions limited the available measurement location to positions within $3.5 \mathrm{~m}$ of such a surface then the measurement location was positioned $1 \mathrm{~m}$ from the surface. The sound pressure level at $1 \mathrm{~m}$ from a single reflecting surface were taken to exceed the value beyond $3.5 \mathrm{~m}$ from the surface by $2.5 \mathrm{~dB}$ and an adjustment of 2.5 $\mathrm{dB}$ was subtracted from the measured results.

Data for speech intelligibility was collected using STIPA PRO app developed by Andrew Smith and Studio Six Digital on iOS, using a transmitter, at the location of the speaker, to produce standard noise signals (provided by the app developer) which were received by the app on the device, placed at the location of the listener in the location.

The importance of study was explained to the staff and written informed consent was obtained for participation in the study.

Data was checked for errors and missed values, and then the corrected data was entered in Microsoft Excel. Data analysis was done using SPSS software licensed version 21. Statistical tests of significance were applied as relevant and $p$-values of less than 0.05 were taken to be significant.

Ethical clearance was obtained from Institution Ethics Committee of Vardhman Mahavir Medical College \& Safdarjung Hospital, New Delhi.

\section{Definitions Used for Study Purpose}

Leq: It is the equivalent continuous sound level in decibels, equivalent to the total sound energy measured over a stated period of time and is also known as the time-average sound level. It is the preferred method to describe sound levels that vary over time, resulting in a single decibel value which takes into account the total sound energy over the period of time of interest.

LAeq: It is the A-weighted equivalent continuous sound level in decibels measured over a stated period of time. Most community and industrial noise measurements are A-weighted so the LAeq descriptor is therefore widely used.

LAmax: A-weighted, maximum, sound level.

Speech Intelligibility: It is the rating of the proportion of speech that is understood.

Speech Transmission Index (STI): It is a metric ranging between 0 and 1 representing the transmission quality of speech with respect to intelligibility by a speech transmission channel.

\section{Result}

Noise levels were recorded in three locations for the pilot study, and were found to be higher than recommended levels at all locations, on both weekdays and weekends as well during the day and night. Laeq levels ranged from 56 $\mathrm{dB}$ in the nephrology ward in the weekends to $89.2 \mathrm{~dB}$ at the OPD atrium on weekdays (Table 1). The maximum noise level (Lamax) was $98.6 \mathrm{~dB}$ in the OPD atrium and $86.1 \mathrm{~dB}$ in the Nephrology ward. The noise levels at night in the ward were found to be higher than during the day time. The presence of family members along with the patient as well as the use of mobile phones by both patients and relatives contributed to this. Unrestricted movement in the wards during the night could also be a reason as there is less supervision of the wards at night.

Forty-five subjects were interviewed for the pilot study, of which, $23(51.1 \%)$ were in the age group of $20-30$ years, and $37(83.3 \%)$ were male. $39(83.3 \%)$ of the study population were of Hindu religion, and $26(57.8 \%)$ were married. 5 (11.1\%) of the study participants were of postgraduate level education, while 15 (33.3\%) were of graduate and 15 (33.3\%) were of senior secondary level education status. $27(60 \%)$ of the study participants were security guards and 13 (28.9) were resident doctors as two of the sites were administrative sites and one of the locations was a hospital ward. 29 (64.4\%) of the study participants worked for greater than one year in the hospital, while 24 (53.3\%) have worked for greater than one year in their current area/ department of work. 42 (93.3) of the study participants work longer than 48 hours in a week. 
Table I.Day and night noise levels in LAeq and LAmax and Speech Transmission Index (STI) in Selected Locations, on weekdays and weekends

\begin{tabular}{|c|c|c|c|c|}
\hline \multirow{2}{*}{$\begin{array}{c}\text { Equivalent Noise Levels ( LAeq) } \\
\text { Site }\end{array}$} & \multicolumn{2}{|c|}{ Weekdays } & \multicolumn{2}{|c|}{ Weekend } \\
\hline & Day (12 hours) & Night (8 hours) & Day (12 hours) & Night (8 hours) \\
\hline \multicolumn{5}{|l|}{ Nephrology Ward } \\
\hline Nursing Station & 65.4 & 59.1 & 63.2 & 57.3 \\
\hline Ward & 58.4 & 60.2 & 56.0 & 58.2 \\
\hline OPD Atrium & 89.2 & 62.2 & 82.2 & 58.9 \\
\hline SSB Gate & 70.1 & 60.1 & 69.2 & 55.6 \\
\hline Maximum noise levels (LAmax) & \multicolumn{2}{|c|}{ Weekdays } & \multicolumn{2}{|c|}{ Weekends } \\
\hline Site & Day & Night & Day & Night \\
\hline \multicolumn{5}{|l|}{ Nephrology Ward } \\
\hline Nursing Station & 85.2 & 65.9 & 86.1 & 64.4 \\
\hline Ward & 80.4 & 71.6 & 82.4 & 69.1 \\
\hline OPD Atrium & 98.6 & 88.5 & 96.0 & 82.2 \\
\hline SSB Gate & 90.5 & 86.3 & 91.4 & 80.7 \\
\hline Speech Transmission Index (STI) & \multicolumn{2}{|c|}{ Weekday } & \multicolumn{2}{|c|}{ Weekend } \\
\hline Site & Day & Night & Day & Night \\
\hline \multicolumn{5}{|l|}{ Nephrology Ward } \\
\hline Nursing Station & 0.55 & 0.84 & 0.62 & 0.88 \\
\hline Ward & 0.80 & 0.90 & 0.82 & 0.90 \\
\hline OPD Atrium & 0.26 & 0.90 & 0.39 & 0.92 \\
\hline SSB Gate & 0.69 & 0.95 & 0.69 & 0.96 \\
\hline
\end{tabular}

Table 2.Annoyance due to noise in hospital staff

\begin{tabular}{|c|c|}
\hline $\begin{array}{c}\text { According to you, is your } \\
\text { workplace noisy? }\end{array}$ & $\mathbf{n}(\%)$ \\
\hline Yes & $24(53.3)$ \\
\hline No & $20(44.5)$ \\
\hline Don't know & $1(2.2)$ \\
\hline Annoyance due to noise $(\mathrm{n}=45)$ & Annoyed $\mathrm{n}(\%)$ \\
\hline Annoyance by numerical scale $(>4)$ & $24(53.3)$ \\
\hline Annoyance by verbal scale $(>=2)$ & $25(55.6)$ \\
\hline Composite annoyance $(>4)$ & $26(57.8)$ \\
\hline
\end{tabular}

24 (53.3\%) of the study participants said that their workplace is noisy, while $26(57.8 \%)$ were found to be annoyed by noise in their workplace (Table 2 ). $66.7 \%$ of the respondents working in the OPD atrium, $53.3 \%$ of those working at the SSB gate and $40 \%$ of the respondents in the nephrology ward reported their workplace to be noisy. $62 \%$ of the respondents said that their workplace was noisy, when the noise level at the time of interview was above $65 \mathrm{~dB}$. $80 \%$ of the respondents working in the OPD atrium and $60 \%$ of the respondents working at the SSB gate were found to be annoyed while only $33.3 \%$ of the respondents working in the nephrology ward were annoyed by noise in their workplace. The factors associated with annoyance in staff due to noise are described in Table 3. Seventy four percent of the respondents under the age of 30 years were not annoyed, while $84.6 \%$ of those above the age of 40 years were found to be annoyed ( $p$-value $=0.003$ ). $72 \%$ of the participants with an education status below the graduate level were found to be annoyed as compared to $40 \%$ of those with an education status of graduate level and above ( $p$-value=0.02). Annoyance due to noise was also associated with department of work ( $p$-value $=0.01$ ), duration of work in the hospital/ week $(p$-value $=0.04)$ and duration of work in current dept/ area of work ( $p$-value $=0.007$ ). $69.5 \%$ of those working greater than 48 hours per week in the hospital were found to be annoyed as compared to $37.5 \%$ of those who worked less than 48 hours per week. $85 \%$ of the respondents working in their current area of work for more than 1 year were found to be annoyed. Annoyance was also associated with noise level at the time of questionnaire administration $(p$-value $=0.04)$ with $68.9 \%$ of the study respondents being annoyed where the noise level was above $65 \mathrm{~dB}$. $70 \%$ of the respondents working at a distance of less than 100 metres from the arterial road $(p$-value $=0.02)$ were annoyed due to noise as compared to $33.3 \%$ of those working further away from the arterial road. 
Table 3.Factors associated with annoyance in staff due to noise in the workplace

\begin{tabular}{|c|c|c|c|c|}
\hline & Total $(n=45)(\%)$ & Annoyed $(n=26)(\%)$ & Not annoyed $(n=19)(\%)$ & p-value \\
\hline \multicolumn{5}{|l|}{ Age } \\
\hline$<=30$ & $23(51.1)$ & $6(26.1)$ & $17(73.9)$ & 0.003 \\
\hline $31-40$ & $9(20)$ & $9(100)$ & 0 & \\
\hline$>40$ & $13(28.9)$ & $11(84.6)$ & $2(15.4)$ & \\
\hline \multicolumn{5}{|l|}{ Sex } \\
\hline Male & $37(82.2)$ & $21(56.7)$ & $16(43.3)$ & 0.08 \\
\hline Female & $8(17.8)$ & $5(62.5)$ & $3(37.5)$ & \\
\hline \multicolumn{5}{|l|}{ Noise at time of Questionnaire } \\
\hline$<=65 \mathrm{~dB}$ & $16(35.6)$ & $6(37.5)$ & $10(62.5)$ & 0.04 \\
\hline$>65 \mathrm{~dB}$ & $29(64.4)$ & $20(68.9)$ & $9(31.1)$ & \\
\hline \multicolumn{5}{|l|}{ Education of Participant } \\
\hline Postgraduate/Professional & $5(11.1)$ & 0 & $5(100)$ & 0.212 \\
\hline Graduate & $15(33.3)$ & $8(53.3)$ & $7(46.7)$ & \\
\hline Senior Secondary School & $15(33.3)$ & $11(73.3)$ & $4(26.7)$ & \\
\hline Secondary School & $9(20)$ & $6(66.7)$ & $3(33.3)$ & \\
\hline Middle School & $1(2.2)$ & $1(100)$ & 0 & \\
\hline \multicolumn{5}{|l|}{ Department of work } \\
\hline Nephrology & $15(33.3)$ & $5(33.3)$ & $10(66.7)$ & 0.01 \\
\hline OPD atrium & $15(33.3)$ & $12(80)$ & $3(20)$ & \\
\hline SSB Gate & $15(33.3)$ & $9(60)$ & $6(40)$ & \\
\hline \multicolumn{5}{|c|}{ Duration of work in hospital/week } \\
\hline$<=48$ hours & $22(48.9)$ & $10(37.5)$ & $12(62.5)$ & 0.04 \\
\hline$>48$ hours & $23(51.1)$ & $16(69.5)$ & $7(30.5)$ & \\
\hline \multicolumn{5}{|c|}{ Duration of work in current area/dept of work } \\
\hline$<=1$ year & $25(55.6)$ & $9(36)$ & $16(64)$ & 0.007 \\
\hline$>1$ year & $20(44.4)$ & $17(85)$ & $3(15)$ & \\
\hline \multicolumn{5}{|c|}{ Perceived Symptoms due to Noise } \\
\hline Present & $33(73.3)$ & $20(46.5)$ & $13(53.5)$ & 0.524 \\
\hline Absent & $12(26.7)$ & $6(50)$ & $6(50)$ & \\
\hline \multicolumn{5}{|l|}{ Distance from Arterial Road } \\
\hline$<=100 \mathrm{~m}$ & $30(66.7)$ & $21(70)$ & $9(30)$ & 0.02 \\
\hline$>100 \mathrm{~m}$ & $15(33.3)$ & $5(33.3)$ & $10(66.7)$ & \\
\hline \multicolumn{5}{|l|}{ Speech Transmission Index } \\
\hline$<=0.75$ & $28(62.2)$ & $15(37.5)$ & $13(62.5)$ & 0.463 \\
\hline$>0.75$ & $17(37.8)$ & $11(69.5)$ & $6(30.5)$ & \\
\hline \multicolumn{5}{|l|}{ Type of Work } \\
\hline Junior Resident & $13(28.9)$ & $3(23)$ & $10(77)$ & 0.05 \\
\hline Nurse & $3(6.7)$ & $2(66.7)$ & $1(33.3)$ & \\
\hline Security Guard & $27(30)$ & $21(77.8)$ & $6(23.3)$ & \\
\hline BVG worker & $2(4.4)$ & 0 & 2 & \\
\hline
\end{tabular}




\section{Discussion}

The noise levels recorded in all three locations of the hospital exceed the recommended levels as per the national laws for silence zones, which stipulate Leq levels of $50 \mathrm{~dB}$ during the day, and $40 \mathrm{~dB}$ during the night time. Equivalent noise levels were as high as $89.2 \mathrm{~dB}$ in the OPD atrium during the day and $62.2 \mathrm{~dB}$ at night. Though noise levels decreased in the OPD atrium and SSB gate at night as compared to the day time, the noise levels in the nephrology ward were found to be slightly higher at night. Noise levels in the weekend were comparatively lower in all three locations. In the study conducted by Khaiwal et al. in 2016 in a tertiary care hospital in Chandigarh, ${ }^{10}$ maximum noise levels were greater than $80 \mathrm{~dB}$ and $70 \mathrm{~dB}$ during the day and night respectively, and noise levels exceeded the regulations in all locations studied. The noise levels inside the wards also exceed the recommended levels inside treatment rooms as stipulated by WHO. There was also a decrease in noise levels in the weekends as compared to the weekdays, similar to our findings. The study found the major sources of noise to be traffic, loud conversations and crowds, similar to our study. According to a study conducted by Vinodhkumaradithyaa et al. in a 2200 bed tertiary hospital in Madurai, ${ }^{11}$ in 2008, noise levels were found to be $70.38 \mathrm{dBA}$ in the morning and $64.46 \mathrm{dBA}$ in the evening, indicating diurnal variation. The study found that noise levels exceeded $70 \mathrm{~dB}$ in the morning, in 10 out of the 14 recording sites.

According to a study conducted by Parvin Nassiri et al. among nurses in 5 hospitals in Iran, ${ }^{7}$ in 2013, average Leq recorded was between $63.32 \mathrm{dBA}$ and $74.60 \mathrm{dBA}$ with highest noise levels in the emergency department, intensive care units and the maternity and new-born care wards. $33.7 \%$ and $36.7 \%$ of the study subjects identified annoyance due to patient conversation with visitors as very high and high respectively. In comparison, $80 \%$ of the study participants found patient and visitor conversation to be a major cause for annoyance. In the study by Khaiwal et al. $74 \%$ reported irritation with loud noise9, while our study found $57.8 \%$ to be annoyed. According to a study conducted by Costa et al., among nursing professionals in a 518 bed teaching hospital in Curitibia, Brazil, ${ }^{12}$ in $2013,76.09 \%$ of the study subjects identified their work environment as noisy as compared to $53.3 \%$ in our study. This difference could be related to the knowledge and awareness about noise and its health effects among the nursing professionals in the former study.

Noise level at the time of questionnaire administration, department/ site of work, duration of work in the hospital per week, distance of site of work from the arterial road were among the factors associated with annoyance in staff due to noise. Findings were similar to the findings in Morrison et al., ${ }^{13}$ Parvin Nassiri et al. ${ }^{7}$ and Pai et al. ${ }^{14}$

According to a study conducted by Ryherd et al. in five different US hospitals, ${ }^{15}$ in 2013, none of the studied units in the hospitals had "good" speech intelligibility (Speech Intelligibility index $>0.75$ ). Many units were found to have "poor" speech intelligibility (SII < 0.45). In our study, Speech Transmission Index (STI) in the nephrology ward room was found to be excellent with 0.80 and 0.90 during the day and night, respectively. However, STI levels in the nursing station of the nephrology ward was 0.55 , which is fair, and 0.26 in the OPD atrium which is considered bad. Low speech intelligibility index levels mean more difficulty in communicating through speech over the background noise levels. This would lead to miscommunication, which is undesirable in an OPD or the nursing station in the ward.

\section{Limitation}

It is a cross-sectional study, and noise recording at the sites is only done on two occasions on the weekday and the weekends, which might not be enough to provide a complete picture of the noise profile of the site. Studying non-auditory symptoms among the staff, like headache, depression, stress, anxiety, sleep disturbance, changes in blood pressure and so on, due to noise in the hospital, would add to the importance of reducing noise in the hospital.

\section{Conclusion}

The present pilot study is concluded that methodology is feasible and able to establish validity and reliability of the tools. Findings are also consistent with observations of other researchers. Hospital noise levels are much higher than the recommended levels for sensitive zones as per national guidelines. IEC campaigns to emphasize the importance of noise as a pollutant and it's auditory and non-auditory effects on both staff and patients, would help modify the behaviour and reduce avoidable sources of noise.

A bigger study throughout the hospital to find the sources of noise specific to each site, following a similar methodology would help in implementing appropriate interventions to mitigate the problem.

\section{Conflict of Interest: None \\ References}

1. Stansfeld S, Haines M, Brown B. Noise and health in the urban environment. Reviews on environmental health 2000; 15(1-2): 43-82.

2. Fritschi L, Brown L, Kim R et al. Burden of disease from environmental noise: Quantification of healthy life years lost in Europe. WHO regional office for Europe 2011.

3. Central Pollution Control Board [Internet]. India: Ministry of Environment, Forest and Climate Change; c2019 [cited 2019 Sep 28]. WHO Guidelines for Noise. Available from: https://cpcb.nic.in/who-guidelinesfor-noise-quality/

4. Busch-Vishniac IJ, West JE, Barnhill C et al. Noise levels 
in Johns Hopkins hospital. The Journal of the Acoustical Society of America 2005; 118(6): 3629-3645.

5. Berglund B, Lindvall T, Schwela DH. World Health Organization. Guidelines for community noise. (1999).

6. Noise Pollution Regulations in India. Central Pollution Control Board, Ministry of Environment \& Forests Govt. of India 2001.

7. Nassiri $\mathrm{P}$, Heidari $\mathrm{H}$, Khadem $\mathrm{M}$ et al. Assessment of noise annoyance and its effects on healthcare staff based on sound pressure level and annoyance scale. International Journal of Occupational Hygiene 2014; 6(1): 23-30.

8. Valente D. STIPA v4 Specification Compliance Study [Internet]. Studio Six Digital; 2002 Feb [cited 2020 Sep 20]. Available from https://studiosixdigital.com/ support/downloads-2/stipav4compliance.pdf

9. Acoustics IS. Assessment of noise annoyance by means of social and socio- acoustic surveys. ISO/TS 15666. International organisation for standardization. 2003.

10. Khaiwal R, Singh T, Tripathy JP et al. Assessment of noise pollution in and around a sensitive zone in North India and its non-auditory impacts. Science of the Total Environment 2016; 566: 981-7.

11. Vinodhkumaradithyaa A, Srinivasan M, Ananthalakshmi l et al. Noise levels in a tertiary care hospital. Noise and Health 2008; 10(38): 11.

12. Costa GD, de Lacerd AB, Marques J. Noise on the Hospital Setting: Impact on Nursing Professionals' Health. Revista CEFAC 2013; 15(3).

13. Morrison WE, Haas EC, Shaffner DH et al. Noise, stress, and annoyance in a pediatric intensive care unit. Critical care medicine 2003; 31(1): 113-119.

14. Pai JY. A study in hospital noise-a case from Taiwan. International Journal of Occupational Safety and Ergonomics 2007; 13(1): 83-90.

15. Ryherd EE, Moeller Jr M, Hsu T. Speech intelligibility in hospitals. The Journal of the Acoustical Society of America 2013; 134(1): 586-595. 